\title{
Depolymerization Kinetics of Self-Immolative Polymers
}

Category

Synthesis of

Materials and

Unnatural Products

\section{Key words}

degradable polymers

controlled depolymerization

cyclization kinetics

This work:<smiles>C=C1C=CC(=O)C=C1</smiles><smiles>COC(=O)Oc1ccc(COC(=O)CCCOC(=O)Oc2ccc(CO)cc2)cc1</smiles><smiles>C=C1C=CC(=O)C=C1</smiles>

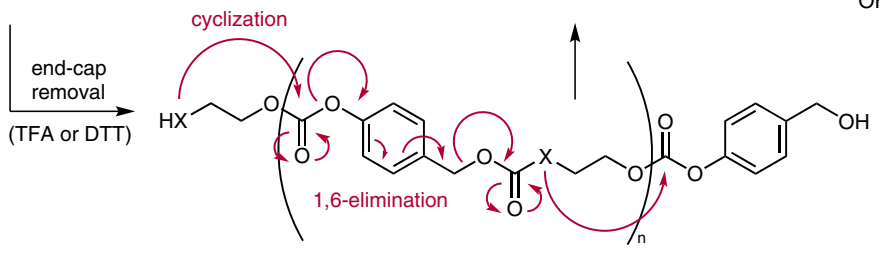

overall depolymerization rates: polymer $3\left(7.8 \times 10^{-2} \mathrm{~min}^{-1}\right)>$ polymer $2\left(2.6 \times 10^{-2} \mathrm{~min}^{-1}\right)>$ polymer $1\left(6.8 \times 10^{-2} \mathrm{~h}^{-1}\right)$

Significance: Self-immolative polymers are materials that degrade into small molecules by an intramolecular cascade reaction upon removal of an end-capping group. Due to their backbones primed for degradation, self-immolative polymers require strategic design and synthesis. Here, Gillies and co-workers have synthesized two new self-immolative polymers with different degradation rates by altering the nucleophilicity and electrophilicity of the functional groups participating in the intramolecular cascade reaction.
Comment: Previously reported self-immolative polymer 1 depolymerizes through a cyclization1,6-elimination pathway with the cyclization being the rate-determining step. By increasing the electrophilicity of the carbonyl by changing it from a carbamate to a carbonate, as seen in polymer $\mathbf{2}$, the rate of depolymerization was increased 500fold. A further increase in depolymerization was achieved when the nucleophile was changed from an amine to a thiol (polymer $\mathbf{3}$ ). Polymer $\mathbf{3}$ is of particular interest due to its redox-sensitive depolymerization, which could be used for cytosolic drug delivery.

SYNFACTS Contributors: Timothy M. Swager, Ellen M. Sletten 